\title{
Modelo de engajamento intersetorial para o desenvolvimento urbano sustentável
}

\author{
Intersectoral Engagement Framework for Urban Sustainable \\ Development
}

Lisandro lusry Abulatif [a] [D, André de Souza Silva [a] [D, Izabele Colusso [a] [D]

[a] Universidade do Vale do Rio dos Sinos, São Leopoldo, RS, Brasil

Como citar: Abulatif, L. I., Silva, A. S., \& Colusso, I. (2021). Modelo de engajamento intersetorial para o desenvolvimento urbano sustentável. urbe. Revista Brasileira de Gestão Urbana, v. 13, e20200077.

https://doi.org/10.1590/2175-3369.013.e20200077

\section{Resumo}

O presente trabalho trata da criação e implementação de um modelo conceitual de engajamento intersetorial, orientado ao desenvolvimento urbano sustentável no município de Guaíba no estado do Rio Grande do Sul. 0 modelo é denominado Estratégia de Desenvolvimento Sustentável, o qual é composto pelas etapas de formação de equipe multidisciplinar, diagnóstico situacional, proposição e alinhamento de intervenções, monitoramento e avaliação, reconhecimento de desempenho e renovação e expansão de atividades e parcerias. A metodologia de pesquisa-ação foi utilizada para a implementação das etapas, combinada com a abordagem de estudo de caso para o relato da experiência e apresentação de resultados. Os resultados indicaram que a Estratégia de Desenvolvimento Sustentável viabilizou melhorias na articulação entre secretarias do executivo municipal, identificação de dados relevantes para uso no processo de planejamento urbano e estímulo ao alinhamento entre representantes dos setores público, setor privado e sociedade civil na elaboração e execução de iniciativas relacionadas à sustentabilidade urbana. Neste sentido, a Estratégia de Desenvolvimento Sustentável foi identificada como um modelo de gestão que pode ser implementado por outras prefeituras para a promoção do desenvolvimento urbano sustentável.

Palavras-chave: Desenvolvimento urbano sustentável. Parcerias intersetoriais. Planejamento urbano. Gestão urbana. Estratégia de desenvolvimento sustentável.

\section{Abstract}

This research deals with the creation and implementation of an intersectoral engagement framework focused on sustainable urban development in the municipality of Guaíba in the state of Rio Grande do Sul. The framework is called the Sustainable Development Strategy, which is composed by the following steps: multidisciplinary partnership building, situational assessment, interventions proposition and alignment, monitoring and evaluation, general review and expansion, renewal of activities and partnerships. The action-research methodology was adopted to implement each of the steps, combined with the case study approach to report the experience and its results. The results indicated that the Sustainable Development Strategy fostered better articulation among municipal executive secretariats, identification of relevant data for use in the urban

LIA é mestre em Arquitetura e Urbanismo, e-mail: labulatif@recursosurbanos.com.br

ASS é doutor em Planejamento Urbano e Regional, e-mail: silandre@unisinos.br

IC é doutora em Planejamento Urbano e Regional, e-mail: icolusso@unisinos.br 
planning process, and better strategic alignment among representatives of the public sector, private sector and civil society focusing the planning and implementation of initiatives related to urban sustainability. In this sense, the Sustainable Development Strategy was identified as managerial framework with potential to be implemented by other municipalities towards the urban sustainable development.

Keywords: Sustainable urban development. Intersectoral partnerships. Urban planning. Urban management. Sustainable development strategy.

\section{Introdução}

Esta pesquisa apresenta a implementação de um modelo estratégico orientado à gestão urbana, o qual tem por base a articulação e engajamento intersetorial (setor público, setor privado e sociedade civil), com vistas ao estímulo e alinhamento de práticas de sustentabilidade urbana no município de Guaíba, no estado do Rio Grande do Sul.

Dados do Banco Mundial informam que, no ano de 2017, a população urbana mundial já havia chegado a 54\% de toda a população, e a $80 \%$ do total da população da região da América Latina e Caribe (The World Bank, 2017). Com este aumento da urbanização, também aumenta a demanda da utilização dos recursos ambientais para o desenvolvimento da vida das cidades. A dinâmica das atividades nas cidades consomem $67 \%$ da produção mundial de energia, geram $75 \%$ dos resíduos, emitem $75 \%$ dos gases que poluem o ar, e são responsáveis por significativa parte do uso desordenado da água potável. Tais dados demonstram que a forma de consumo de recursos ambientais é incompatível com o ponto de equilíbrio entre a exploração ambiental e a demanda real de recursos (Institute for the Advanced Study of Sustainability, 2016; Leite \& Awad, 2012).

Com tal realidade em vista percebe-se que o crescimento das populações urbanas, e o consequente aumento de demanda de recursos ambientais para o desenvolvimento das cidades necessitam de uma abordagem de operacionalização da sustentabilidade, que viabilize condições de vida aceitáveis para as futuras gerações de moradores do ambiente urbano. Neste sentido, a questão que se coloca é "como engajar os setores público, privado e sociedade civil para transformar ideias sobre desenvolvimento sustentável em práticas que gerem resultados mensuráveis?".

A hipótese considerada é de que a aplicação de um modelo de gestão colaborativa pode servir de indutor de engajamento e alinhamento progressivos dos setores público, privado e sociedade civil, por meio de iniciativas relacionadas ao desenvolvimento urbano sustentável.

O tema deste trabalho aborda a questão do desenvolvimento urbano sustentável, na perspectiva do "ODS 11 - Cidades e Comunidades Sustentáveis" proposto pela Organização das Nações Unidas ${ }^{1}$. Este foco na sustentabilidade das cidades surge da crescente relevância que os sistemas urbanos têm adquirido ao longo do tempo, à medida que as populações urbanas aumentam e, consequentemente, apresentam desafios de planejamento e gestão para a presente geração, e potencialmente para as próximas gerações também.

Esta pesquisa, a qual é parte de um projeto de mestrado, se propõe a apresentar o processo de implementação de um sistema de colaboração proativa, denominado Estratégia de Desenvolvimento Sustentável (EDS), o qual visa estimular o engajamento de segmentos sociodemográficos ${ }^{2}$ urbanos, na cooperação para o desenvolvimento urbano sustentável. A aplicação deste processo ocorre no município de Guaíba/RS, com população de 99.334 no ano de 2017 (ano de início da pesquisa), o qual faz parte da Região Metropolitana de Porto Alegre (DATASUS, 2017). Nesta região, o município encontra-se em situação de expectativa de crescimento populacional, originado de pessoas vindas de outros municípios da Região

${ }^{1}$ Os ODS's fazem parte da agenda global de desenvolvimento sustentável das Nações Unidas e são compostos por objetivos, metas a serem alcançados até o ano de 2030. Ao todo, são dezessete objetivos: (1) Erradicação da pobreza;

(2) Fome zero e agricultura sustentável; (3) Saúde e bem-estar; (4) Educação de qualidade; (5) Igualdade de gênero; (6) Água potável e saneamento; (7) Energia acessível e limpa; (8) Trabalho descente e crescimento econômico; (9) Indústria, inovação e infraestrutura; (10) Redução das desigualdades; (11) Cidades e comunidades sustentáveis; (12) Consumo e produção responsáveis; (13) Ação contra a mudança global do clima; (14) Vida na água; (15) Vida terrestre; (16) Paz, justiça e instituições eficazes; (17) Parcerias e meios de implementação.

20 termo "segmentos sociodemográficos" corresponde à ideia de microcultura, a qual é conceituada como um subgrupo de uma sociedade, que possui características próprias como linguagem, expectativas de regras e formas de "fazer as coisas" (Spradley \& McCurdy, 2006), como por exemplo grupos segmentos profissionais ou moradores de determinado bairro. 
Metropolitana e a intensificação da ocupação do uso do solo urbano e expansão da área urbana nos próximos anos, o que poderá contribuir para urbanização desordenada, impacto ambiental negativo, incluindo o agravamento da destinação inadequada dos resíduos do município (Soares \& Fedozzi, 2016).

Com base neste cenário, este trabalho se propõe a avaliar a viabilidade de um processo de engajamento social focado no desenvolvimento urbano sustentável, o qual tem por base a articulação intersetorial e o engajamento da comunidade local em ações voltadas à promoção da sustentabilidade urbana. A pesquisa foi realizada entre os meses de junho de 2017 e julho de 2018, em um total de doze meses, no âmbito do Executivo Municipal de Guaíba (RS) e o envolvimento de instituições parceiras de demais setores da sociedade.

Este artigo está organizado na forma apresentada a seguir: Inicialmente são apresentados o modelo conceitual da EDS e o método de implementação do processo no município de Guaíba (RS). Em seguida, são apresentados os resultados obtidos. Por fim é realizada uma discussão dos resultados, combinada com as considerações finais, realizadas pelos autores, abrangendo as principais etapas da pesquisa, potencial de aplicabilidade em outras localidades e sugestões para futuras pesquisas.

\section{O Modelo da Estratégia de Desenvolvimento Sustentável}

A EDS é concebida como um processo cíclico composto por seis etapas fundamentais: (1) Formação de Parcerias, (2) Diagnóstico e Priorização, (3) Processo de Criação e Engajamento, (4) Monitoramento, Avaliação e Alinhamento, (5) Revisão Geral e Reconhecimento, e (6) Renovação e Expansão. Este modelo tem por base respeitar a cultura local de onde é implementado, de modo a aumentar as chances de que as comunidades locais se apropriem do processo e se engajem em sua operacionalização, o que também é reforçado conceitualmente por Cardita e Di Pietro (Cardita \& Pietro, 2010). A Erro! Fonte de referência não encontrada. apresenta o fluxo de processo das etapas da EDS.

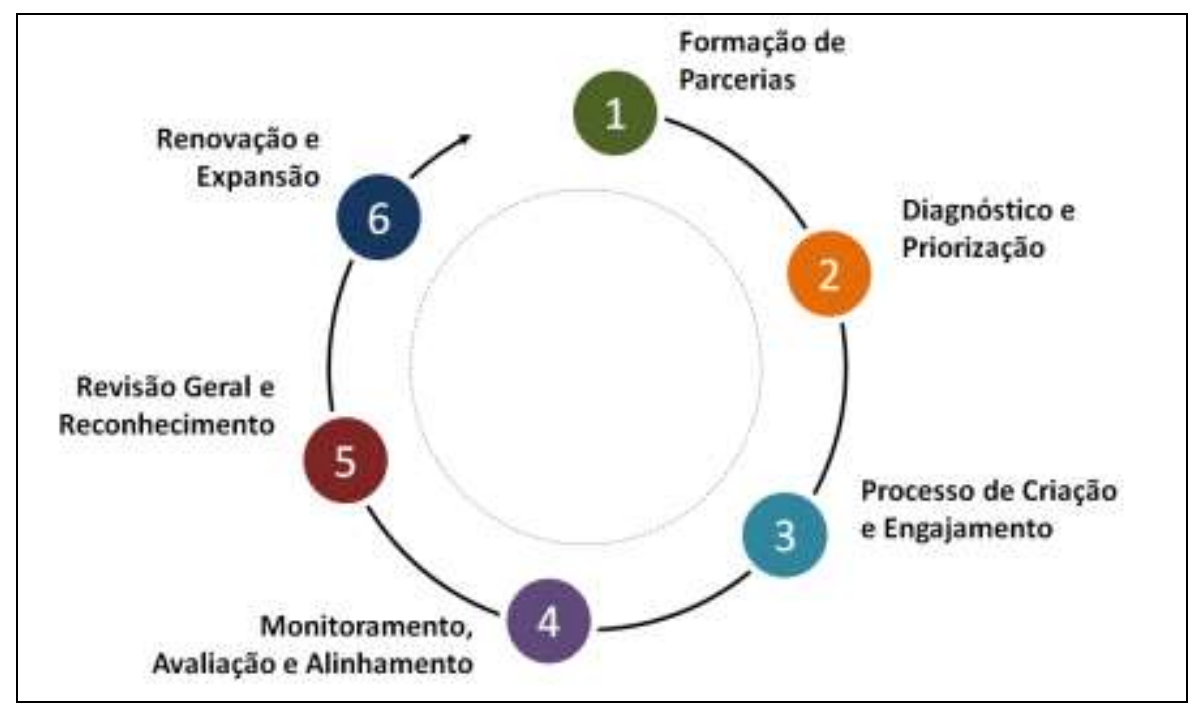

Figura 1 - Diagrama das seis etapas da Estratégia de Desenvolvimento Urbano Sustentável. Fonte: Adaptado de Cardita e Di Pietro (2010).

O processo é iniciado a partir da etapa Formação de Parcerias com vistas à constituição de uma equipe multidisciplinar para a implementação da EDS. Também são identificadas potenciais parcerias complementares que poderão contribuir com o processo através da disponibilização de dados secundários (relacionados às metas do ODS 11) ou participação em ações voltadas ao desenvolvimento urbano sustentável ${ }^{3}$.

Na etapa Diagnóstico e Priorização são definidas as temáticas prioritárias a ser trabalhadas em termos de desenvolvimento urbano sustentável. Esta escolha tem por base as metas do ODS 11. Para tal finalidade

\footnotetext{
${ }^{3}$ As metas são relacionadas aos seguintes temas: habitação segura e adequada, transportes seguros e sustentáveis, urbanização inclusiva e participativa, proteção do patrimônio cultural, redução de pessoas afetadas por catástrofes e acesso a espaços públicos sustentáveis e seguros.
} 
é realizada uma atividade de levantamento de dados do município, relacionados às metas do ODS a fim de que seja possível definir uma ordem de prioridades de ação e identificar necessidades e problemas que deverão ser abordados na etapa seguinte.

Na etapa Processo de Criação e Engajamento são criados grupos de iniciativas para o desenvolvimento urbano sustentável. Os grupos são organizados por áreas temáticas como: (i) Educação, (ii) Infraestrutura, (iii) Legislação e Regramento e (iv) Projetos Complementares. Este processo visa abordar temas específicos para a cidade a partir de ações de iniciativa do poder público local com a utilização de parcerias intersetoriais. São criados também os Sistemas de Engajamento e Resultados Progressivos (SERP). 0 termo "progressivos" visa sugerir e encorajar a possibilidade de expansão de novas parcerias e resultados mais elevados ao longo do tempo, à medida em que o sistema seja renovado (o que se dá, via de regra, com base anual).

Estes sistemas são desenvolvidos com o objetivo de abordar segmentos sociodemográficos específicos da cidade, de modo despertá-los e engajá-los com a temática do desenvolvimento urbano sustentável. São sistemas de adesão voluntária, que funcionam através do estabelecimento de critérios mínimos de desempenho esperados para cada segmento, que tem por objetivo estimular novas práticas orientadas ao desenvolvimento urbano sustentável, de modo que cada segmento, ao evoluir em termos das práticas e comportamentos adotados, também se torne um influenciador do sistema urbano (Cardita \& Pietro, 2010). Esta abordagem se dá com base na proposição de Pascale (1999) e Johnson (2003) de que comportamentos esperados em sistemas complexos, como os sistemas urbanos, podem ser "provocados" por meio de estímulos realizados em um contexto de regras simples e claras, as quais podem ser concebidas a partir de um contexto projeção de um futuro desejado para uma dada cidade (como por exemplo o ODS 11).

$\mathrm{Na}$ etapa Monitoramento, Avaliação e Alinhamento, é realizado o acompanhamento da execução e implementação das iniciativas planejadas pela equipe EDS. Quando são encontrados baixo desempenho ou falhas de execução, são propostas medidas de correção e alinhamento para solução dos problemas encontrados. Eventualmente, podem também ser propostas possibilidade de melhorias.

A etapa de Revisão Geral e Reconhecimento, é o momento quando são avaliados os resultados gerais do processo de trabalho. Esta atividade é realizada com a participação do prefeito, gestores das secretarias principais e equipe EDS. Os principais interessados, parceiros em geral e representantes da comunidade também devem ser convidados a participar deste momento com o objetivo de fortalecer a responsabilidade compartilhada pelo desenvolvimento urbano sustentável e demonstrar publicamente sua relevância para o poder público local. Também é neste momento que são realizadas as entregas das certificações de desempenho relacionadas aos SERP.

Já na etapa Renovação e Expansão, o seu foco visa operacionalizar o caráter dinâmico e de melhoria contínua do processo da Estratégia. Neste ponto, são propostas reflexões e melhorias todos os anos, a fim de renovar e expandir o processo, que será reiniciado de forma contínua e progressiva. Programas, projetos sistemas poderão ser finalizados, substituídos ou atualizados, inclusive em termos de parceiros.

Neste ponto, a EDS é reiniciada em suas etapas para um novo ciclo anual de operação. Cabe destacar que o reinício se dá a partir da etapa dois da Estratégia, na qual os dados levantados anteriormente são atualizados e com base na sua análise os programas podem ser atualizados por meio da atualização de projetos e sistemas existentes ou criação de novos. Assim, as demais etapas são percorridas em um novo ciclo iterativo, viabilizando a renovação do processo.

\section{Processo de aplicação da pesquisa}

A metodologia adotada foi o de pesquisa-ação, na qual se é planejado e se realiza a partir de uma intervenção sobre um problema coletivo. Nesta, os pesquisadores e os participantes relevantes da situação da realidade a ser investigada estão envolvidos de modo cooperativo e participativo e que objetiva simultaneamente a intervenção, a elaboração e o desenvolvimento de teoria (Collis \& Hussey, 2005; Vergara, 2010).

As etapas essenciais de um processo de pesquisa-ação, segundo Tripp (2005), são as seguintes: (i) Planejamento de uma possível melhoria, (ii) Implementação da melhoria desejada, (iii) Descrição dos efeitos da implantação, e (iv) Avaliação dos resultados da implementação.

A partir da delimitação da pesquisa, apresentação conceituação das etapas da EDS e também da metodologia de pesquisa-ação, as fases para a operacionalização deste trabalho foram executadas conforme 
descrito na Erro! Fonte de referência não encontrada.. Destaca-se, entretanto, que a atividade de pesquisa bibliográfica, embora tenha um momento de destaque inicial, constituiu-se em uma prática subjacente e contínua — tendo em vista o refinamento metodológico da implementação da pesquisa — dado o caráter dinâmico do processo de pesquisa-ação e a própria natureza da EDS.

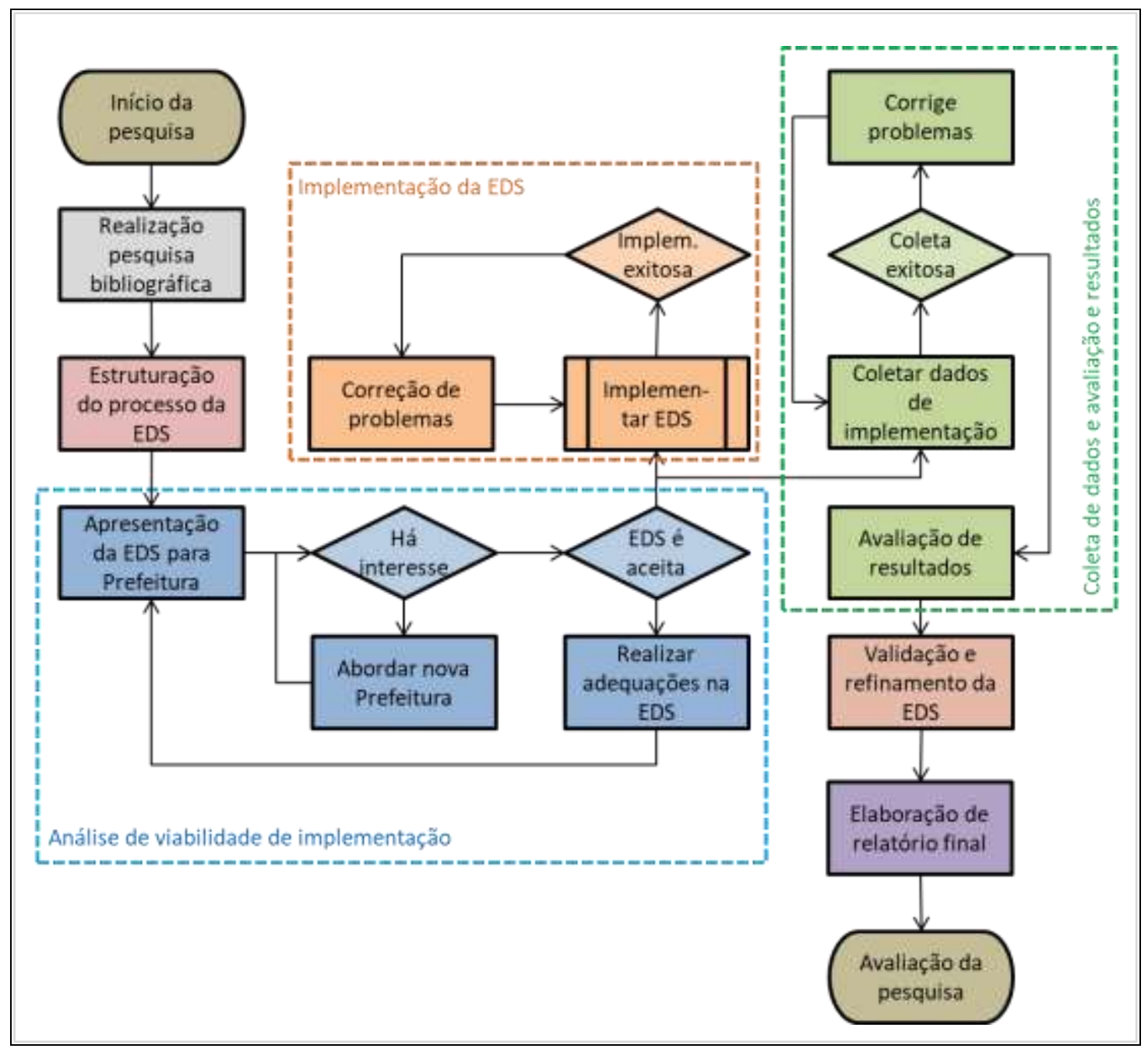

Figura 2 - Processo de implementação da pesquisa, contendo as etapas de início, análise de viabilidade de implementação, implementação da EDS, coleta de dados e avaliação de resultados e finalização da pesquisa. Fonte: Elaboração própria.

A realização da pesquisa foi iniciada a partir da etapa de análise de viabilidade de implementação, na qual foi realizado contato com a prefeitura municipal de Guaíba (RS) para apresentação da proposta de trabalho "pesquisa-ação", a fim de que se defina se há interesse do Executivo Municipal receber a intervenção. Para isto, foram realizadas duas reuniões de apresentação da proposta da pesquisa, nas quais participaram os secretários de Planejamento Urbano e Comunicação e Ação Comunitária, e técnicos das Secretarias de Educação, Mobilidade Urbana e Segurança Pública e Saúde. Em ambas as reuniões foi enfatizada a oportunidade de uso da EDS como instrumento de estímulo para a formação e consolidação de parcerias, com vistas ao desenvolvimento de ações relacionadas ao ODS-11.

Durante as reuniões foi percebida a oportunidade de utilizar o estímulo de formação de parcerias, especialmente com o setor privado e a sociedade civil, para estimular o engajamento da população às atividades de discussão pública da atualização do Plano Diretor Municipal de Guaíba (RS), fato que aumentou o interesse do município em aceitar a realização da pesquisa. Após avaliação interna dos gestores e técnicos da prefeitura de Guaíba (RS) houve o aceite da implementação do processo. Sendo então realizada nova reunião de apresentação da metodologia em nível de detalhamento operacional, de forma a contextualizar os gestores e técnicos locais sobre os processos a serem implementados, bem como dos recursos que serão necessários (principalmente em termos de disponibilização de técnicos para compor uma equipe de trabalho para atuar em 
conjunto com o pesquisador). Após a realização das ações descritas anteriormente, foi dado início à operacionalização das seis etapas da EDS, conforme apresentado a seguir:

\section{Formação de parcerias}

Esta etapa ocorreu em dois níveis, sendo o primeiro a definição da equipe de trabalho, composta por oito técnicos (representantes das Secretarias de Planejamento Urbano, Comunicação e Ação Social, Educação, Saúde e Mobilidade Urbana e Segurança Pública), supervisionada pelo pesquisador. Já o segundo nível de parcerias ocorreu por meio convites a instituições públicas (escolas municipais de ensino fundamental), privadas (empresas locais) e da sociedade civil (associações de bairro e igrejas organizações que possuem boa capilaridade no território do município).

\section{Diagnóstico e priorização}

Com base na proposta do ODS-11, a equipe técnica optou por direcionar esforços inicialmente para as seguintes metas: (i) aumentar a urbanização inclusiva, sustentável e as capacidades para o planejamento e gestão de assentamentos humanos participativos, integrados e sustentáveis, (ii) redução do impacto ambiental negativo per capita nas cidades, e (iii) promover acesso universal a espaços públicos seguros, inclusivos, acessíveis e verdes. Já o levantamento de dados referentes aos temas escolhidos foi obtido pela coleta de dados em sistemas de informação do município, e também contou com a oportunidade de utilizar um levantamento de dados prévio, relacionado ao plano de desenvolvimento urbano de longo prazo do município. Todas as informações obtidas subsidiaram as etapas seguintes do processo.

\section{Criação e engajamento}

Como base desta etapa, foi realizado o levantamento das atividades e projetos, já em prática pelo Executivo Municipal, que possuíssem relação com as temáticas previamente definidas visando construir uma caracterização mínima das ações existentes. A descrição das ações foi sistematizada por meio de dados básicos como (i) nome da ação, (ii) objetivo, (iii) secretaria responsável, (iv) outras secretarias ou organizações envolvidas e (v) meta do ODS-11 a qual possuía conexão. Levando em consideração que a proposição de novas intervenções, no âmbito do Executivo Municipal, demandariam a observância de fluxos administrativos internos com períodos de tempo incompatíveis com o período de tempo da pesquisa, optouse por procurar consolidar as ações já existentes ao invés da criação de novas intervenções. Porém, mesmo assim, foi criada e executada uma iniciativa de comunicação social, por meio de mídia impressa, desenvolvida em conjunto entre o pesquisador e a equipe técnica, para engajar a população urbana no processo de atualização do Plano Diretor Municipal de Guaíba. O material que explicava o propósito do Plano e a sua relação com os ODS's foi distribuído em pontos chave da cidade e também às instituições que aderiram ao processo de parceria proposto no contexto da EDS.

A exceção foi a proposição e implementação dos Sistemas de Engajamento e Resultados Progressivas (SERP). Para que fossem implementados, foram definidos segmentos sociodemográficos, para os quais foi elaborada uma proposta de engajamento voluntário, baseada em critérios pré-definidos e alinhados às metas do ODS-11 priorizadas pela equipe de gestão da EDS. Os segmentos escolhidos para iniciar o processo foram as escolas municipais e igrejas da cidade, com possibilidade de expansão também para as associações de bairro. Porém, quanto às associações de bairro, foi identificado que devido a fragilidades da capacidade de mobilização das mesmas (durante o período da pesquisa), a atitude mais prudente seria a de auxiliá-las a se consolidarem para, posteriormente, buscar engajá-las no processo do SERP. Sendo assim, o foco de atuação para as associações de bairro foi o de mobilizá-las para a participação no processo de revisão do Plano Diretor Municipal por meio da realização de reuniões para a apresentação da proposta de revisão do Plano. Aderiram ao SERP quatorze escolas municipais e três igrejas (consideradas somente as instituições que após aderirem ao sistema foram até ao final do ciclo do processo de participação).

A operacionalização do sistema de engajamento destas organizações de um conjunto de critérios prédefinidos, o qual combina dois blocos de pontuação, sendo o primeiro o de promoção de boas práticas de 
sustentabilidade urbana (relacionadas às metas do ODS-11 priorizadas pela equipe da EDS) somada à captação de parcerias junto à região da cidade a qual pertence, e o segundo relacionado aos resultados obtidos por meio das práticas implementadas. Assim, cada organização teve liberdade para escolher qual temática específica abordar. A pontuação para cada critério foi estabelecida em uma escala de zero a cem pontos, atribuindo certificados de reconhecimento por boas práticas relacionadas ao desenvolvimento urbano sustentável, nos níveis: três estrelas ( 51 a 69 pontos), quatro estrelas ( 70 a 89 pontos) e cinco estrelas ( 90 a 100 pontos). 0 ciclo de desenvolvimento das atividades ocorreu entre os meses de agosto de 2017 e fevereiro de 2018. As Tabelas 1 e 2 apresentam os critérios aplicados para as escolas e igrejas respectivamente.

Tabela 1 - Critérios de certificação para escolas municipais, 2017

\begin{tabular}{lll}
\hline & Item de certificação & Pontuação \\
\hline Práticas & Realização de um projeto contemplando o tema "desenvolvimento urbano & 20 \\
& sustentável" & 10 \\
& Expansão do projeto para a comunidade escolar. & 10 \\
& Protagonismo dos alunos ou familiares na elaboração e execução do projeto realizado & 10 \\
& Captação de parcerias para o projeto realizado & 50 \\
Resultados & Atingiu 100\% da meta do projeto & 40 \\
& Atingiu entre $80 \%$ e $99 \%$ da meta do projeto & 30 \\
& Atingiu entre $60 \%$ e $79 \%$ da meta do projeto & 20 \\
Certificação: 51 a 69 pontos - 3 estrelas, 70 a 89 pontos - 4 estrelas, 90 a 100 pontos - 5 estrelas &
\end{tabular}

Fonte: Elaboração própria.

Tabela 2 - Critérios de certificação para igrejas, 2017

\begin{tabular}{lll}
\hline & Item de certificação & Pontuação \\
\hline Práticas & Projeto relacionado ao ODS 11 "Cidades e comunidades sustentáveis" & 20 \\
& Participação de no mínimo dez integrantes nas reuniões de revisão do plano diretor & 10 \\
& Ação direcionada ao tema "redução do impacto ambiental negativo per & 10 \\
& capita nas cidades" & 10 \\
& Envolvimento da comunidade do entrono da instituição, no projeto realizado & 50 \\
Resultados & Atingiu 100\% da meta do projeto & 40 \\
& Atingiu entre $80 \%$ e $99 \%$ da meta do projeto & 30 \\
& Atingiu entre $60 \%$ e $79 \%$ da meta do projeto & 20 \\
& Atingiu entre $50 \%$ e $59 \%$ da meta do projeto & \\
Certificação: 51 a 69 pontos - 3 estrelas, 70 a 89 pontos - 4 estrelas, 90 a 100 pontos - 5 estrelas &
\end{tabular}

Fonte: Elaboração própria.

Para auxiliar o registro de informações por parte das instituições participantes e também a gestão do processo, por parte da equipe técnica e do pesquisador, foi desenvolvido um software, disponibilizado via internet, no qual todos os participantes do processo pudessem inserir suas informações e acompanhar resultados por meio de recursos de visualização de dados. As questões técnicas de funcionamento do software (hospedagem, despesas de desenvolvimento, manutenção e atualizações) foram administradas pelo pesquisador, o qual também forneceu treinamento para a equipe técnica e para representantes das instituições participantes do processo (previamente indicados para receber a capacitação).

A equipe técnica realizou o cadastro das instituições participantes e os critérios de avaliação e pontuações para a certificação. As instituições participantes passaram, então, a realizar o registro dos projetos realizados, parcerias captadas e demais elementos referentes ao processo de certificação. Com este fluxo de trabalho estabelecido através deste software on-line, foi possível para a equipe técnica e para o pesquisador, acompanhar em tempo real o desempenho das instituições, na medida em que estas realizavam o registro de suas atividades no sistema. Foi garantido que todos os dados inseridos no sistema seriam de propriedade da prefeitura de 
Guaíba (RS), e que a aplicação seria disponibilizada de forma gratuita e ininterrupta para uso da equipe técnica, mesmo após o término do período de realização da pesquisa.

Entre as escolas, os temas escolhidos para a realização de seus projetos foram: (i) espaços públicos seguros, inclusivos, acessíveis e verdes, (ii) redução do impacto ambiental negativo per capita, e (iii) requalificação do ambiente escolar. Entre as igrejas, todas escolheram desenvolver projetos relacionados a espaços públicos seguros, inclusivos, acessíveis e verdes. Para o apoio ao desenvolvimento de seus projetos, estas organizações captaram 21 parceiros, sendo dois do setor público, treze do setor privado e seis da sociedade civil. 0 elevado número de parcerias do setor privado, em relação às demais parcerias, é consequência da proximidade e relação de confiança, que as instituições que participaram do processo de certificação, possuem junto à sua comunidade local. A apresentação da EDS e do processo de certificação como um método bem definido, inclusive com atividades dedicadas ao monitoramento, foi mencionado por um dos parceiros do setor privado, como característica que inspira confiança para que a empresa pudesse, no contexto de sua parceria, fazer aportes de financiamento de atividades tendo condições de acompanhar de forma objetiva o efeito o uso de seus recursos doados.

\section{Monitoramento, avaliação e alinhamento}

Esta etapa ocorreu no mês de março de 2018, envolvendo o pesquisador e a equipe de trabalho do município. 0 principal instrumento de obtenção de dados para o monitoramento e avaliação foi o software desenvolvido para o registro das atividades das instituições. Por meio dele foi realizada uma análise dos registros de participação das organizações que aderiram ao SERP, com foco na capacidade de participação de cada organização (se conseguiu realizar as atividades a que se propôs) e no fechamento da pontuação do processo de certificação do SERP (ocorrido no ciclo de atividades de agosto de 2017 a fevereiro de 2018). Este processo permitiu identificar que as organizações que não receberam certificação de três, quatro ou cinco estrelas (duas escolas e duas igrejas), não o fizeram devido a contingências internas e não por inconsistências dos critérios de avaliação propostos.

As atividades de avaliação e alinhamento levaram em conta fatores como a quantidade de instituições certificadas, os projetos apresentados por cada instituição, a captação de parcerias e o efeito do processo na percepção sobre desenvolvimento urbano sustentável entre os integrantes das instituições no âmbito do SERP, também a percepção da equipe técnica quanto aos eventuais benefícios da implementação do processo da EDS como um todo, com o propósito de que fossem identificadas eventuais necessidades de realinhamento do processo. Neste sentido, foi identificado que as instituições demonstraram um bom nível de motivação e engajamento no processo, porém com a necessidade da presença mais atuante por parte de integrantes da equipe técnica junto às instituições parceiras. Também foi identificada a necessidade de reorganização das atividades da equipe técnica, ou o acréscimo de novos integrantes a ela, a fim de melhor distribuir a carga das atividades de gestão do processo de certificação.

As atividades de avaliação e alinhamento seguiram também ao longo das etapas seguintes do processo. Tal fato foi necessário em virtude da pesquisa, como um todo, ter entrado em seu período de avaliação geral, com vistas à apresentação geral de resultados e finalização da mesma.

\section{Revisão geral e reconhecimento}

Foi então realizada uma cerimônia de certificação das organizações participantes, com a participação dos secretários envolvidos no processo e do prefeito municipal, os quais entregaram as certificações para as organizações participantes. Receberam os certificados três estrelas (três escolas), quatro estrelas (oito escolas e uma igreja), cinco estrelas (duas escolas). Não atingiram a pontuação mínima duas escolas e duas igrejas.

Com base nesta avaliação, foi realizada a atualização dos critérios de certificação do SERP para o início do ciclo referente ao ano de 2018 (com início logo após a cerimônia de certificação, em março de 2018, e 
encerramento em dezembro de 2018) ${ }^{4}$. Este processo, desde a concepção dos critérios de certificação até a renovação dos critérios para o início do ciclo de 2018, é apresentado na Erro! Fonte de referência não encontrada..

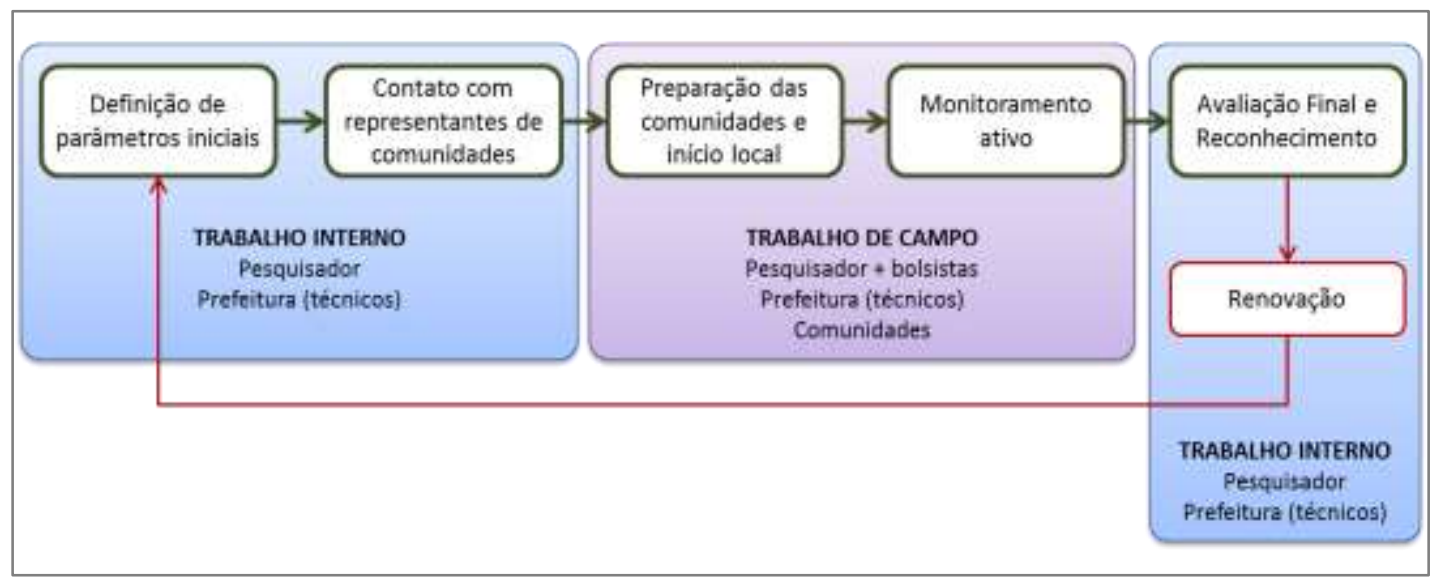

Figura 3 - Processo de operacionalização dos SERP, contendo as atividades de definição de parâmetros e contato com representantes de comunidades, preparação das comunidades e monitoramento ativo, e avaliação e renovação do processo. Fonte: Elaboração própria.

Renovação e expansão: Esta etapa teve foco direcionado para o desenvolvimento da consolidação do SERP no município. As iniciativas foram concentradas nas atividades de refinamento dos critérios de certificação, renovação e fortalecimento de parcerias, e capacitação institucional. Esta ação foi discutida e elaborada em parceria com técnicos da equipe de técnicos e validado junto às instituições parceiras. Quanto à renovação e expansão da adesão das instituições ao SERP, foi realizada a proposta de renovação às instituições participantes e convites foram realizados a novas instituições. Foram 16 escolas em 2017 e também 16 em 2018, quanto às igrejas, foram 3 em 2017 e 4 em 2018. Entretanto, embora a quantidade total de instituições tenha permanecido estável, 6 instituições não escolas não haviam renovado a parceria até a finalização da pesquisa, e uma igreja optou por direcionar suas atividades para a área de assistência social no ano de 2018, ao invés nos temas propostos no contexto da EDS.

\section{Coleta de dados para avaliação da pesquisa}

Após este processo de aplicação da metodologia, a partir do mês de abril de 2018 foi iniciado o processo de avaliação do impacto da utilização da EDS e do SERP, mais especificamente junto à equipe técnica do município de Guaíba, (a qual participou da implementação do processo) e das escolas e igrejas que participaram do processo de certificação (para avaliar as percepções sobre desenvolvimento urbano sustentável após a utilização da metodologia da EDS).

Para este fim, foram aplicados dois questionários, um para a equipe técnica (com seis respondentes) e outro para as organizações que participaram da certificação, sendo um estruturado e o outro semiestruturado, respectivamente. No caso das escolas os respondentes foram professores (44 respondentes de 223 professores), e no caso das igrejas foram os frequentadores das mesmas (51 respondentes de 500 frequentadores). Sendo assim, o tamanho amostral para a média das respostas permitiu um nível de confiança de $95 \%$ e erro máximo esperado de 0,5. Não houve necessidade de utilização de Termo de Consentimento Livre e Esclarecido devido ao fato de os dados de identificação dos respondentes não terem sido coletados. Mesmo assim, foi realizada uma nota nos questionários informando o propósito da pesquisa, opção do direito de recusa ao preenchimento sem qualquer prejuízo ao

\footnotetext{
${ }^{4}$ Como o processo do SERP foi inserido no processo de trabalho da prefeitura municipal de Guaíba, optou-se pelo encerramento no mês de dezembro para que coincidisse com o final do ano letivo das escolas envolvidas. Em função deste fato, este ciclo de atividades ficou fora do escopo desta pesquisa, por não ser possível a coleta de dados em tempo oportuno para finalização da mesma.
} 
entrevistado, garantia de sigilo e possibilidade de acesso aos resultados produzidos a qualquer momento de interesse do respondente, caso aceitasse responder ao questionário.

\section{Resultados}

A apresentação dos resultados é realizada em dois blocos. 0 primeiro demonstra os resultados referentes à aplicação dos questionários de avaliação sobre a percepção sobre o tema de desenvolvimento urbano sustentável, junto às organizações participantes do processo de certificação do SERP. 0 segundo bloco apresenta os resultados referentes aos efeitos da implementação da EDS em relação ao impacto gerado nos grupos de profissionais e parceiros envolvidos no processo.

\section{Percepções sobre o tema de desenvolvimento urbano sustentável}

O Gráfico 1 apresenta a frequência relativa dos vinte termos mais frequentes utilizados nas respostas de escolas e igrejas para a pergunta "O que é necessário para que uma cidade se desenvolva de forma sustentável?". É possível identificar que, tanto para escolas como para as igrejas, houve uma maior ênfase ao uso de termos relacionados à sustentabilidade ambiental, como "lixo", "coleta seletiva" e "reciclagem". Entretanto, surgiram também termos relacionados ao espaço urbano como "áreas", "parques", "praças" e "ruas". Com base nesta análise, é possível inferir que os integrantes das instituições parceiras ainda vinculam com mais ênfase a ideia da cidade sustentável à questão ambiental, e uma tendência mais suavizada de vincular a questão espacial e de ambiente edificado com a concepção de cidade sustentável.

Frequência relativa de termos mais utilizados nas respostas sobre desenvolvimento urbano sustentável.

\begin{tabular}{|c|c|c|}
\hline & Escolas & Igrejas \\
\hline $1^{\circ}$ & lixo & 0,033 \\
\hline $2^{\circ}$ & coleta seletiva $\quad 0,024$ & reciclagem \\
\hline $3^{\circ}$ & reciclagem $\quad 0,019$ & coleta seletiva \\
\hline $4^{\circ}$ & uso & qualidade \\
\hline $5^{\circ}$ & água & bairros \\
\hline $6^{\circ}$ & educação $\quad 0,015$ & projetos \\
\hline $7^{\circ}$ & energia $\quad 0,014$ & população \\
\hline $8^{\circ}$ & qualidade $\quad 0,010$ & 0,010 \\
\hline $9^{\circ}$ & áreas 0,010 & água 0,010 \\
\hline $10^{\circ}$ & conscientização $\quad 0,009$ & conscientização \\
\hline $11^{\circ}$ & população $\quad 0,009$ & 0,009 \\
\hline $12^{\circ}$ & indústrias $\quad 0,009$ & planejamento \\
\hline $13^{\circ}$ & fiscalização $\quad 0,008$ & cuidar 0,007 \\
\hline $14^{\circ}$ & transporte $\quad 0,008$ & educação 0,007 \\
\hline $15^{\circ}$ & preservação 0,008 & praças 0,007 \\
\hline $16^{\circ}$ & recursos $\quad 0,007$ & limpeza 0,007 \\
\hline $17^{\circ}$ & planejamento 0,007 & lazer 0,007 \\
\hline $18^{\circ}$ & cidade $\quad 0,007$ & saúde 0,007 \\
\hline $19^{\circ}$ & coletivo 0,006 & ruas 0,007 \\
\hline $20^{\circ}$ & parques 0,006 & pessoas 0,007 \\
\hline
\end{tabular}

Gráfico 1 - Frequência relativa de termos mais utilizados nas respostas sobre desenvolvimento urbano sustentável. Fonte: Elaboração própria. 
O Gráfico 2 apresenta a frequência relativa dos vinte termos mais frequentes utilizados nas respostas de escolas e igrejas para a questão "Liste até dez termos com os quais você explicaria 'impacto ambiental negativo de uma cidade'”. É possível identificar que, tanto para escolas como para as igrejas, a distribuição dos termos abrange temas como o manejo de resíduos sólidos (lixo), utilização (apropriada ou não) de água e energia elétrica, saneamento básico e poluição sonora, demonstrando uma compreensão geral razoavelmente abrangente da questão do tema, para que seja abordado em projetos futuros.

Frequência relativa de termos mais utilizados nas respostas sobre impacto ambiental negativo.

\begin{tabular}{|c|c|c|c|}
\hline \multicolumn{3}{|r|}{ Escolas } & Igrejas \\
\hline $1^{\circ}$ & poluiç̧̃å & 0,049 & 0,039 \\
\hline $2^{6}$ & Iixo & 0,040 & poluição \\
\hline $3^{e}$ & água & 0,026 & 0,033 \\
\hline $4^{6}$ & ruas & 0,017 & água \\
\hline $5^{*}$ & esgoto & 0,016 & esgoto \\
\hline $6^{6}$ & ar & 0,014 & descarte 0,016 \\
\hline 76 & desmatamento & 0,013 & rios 0,016 \\
\hline 8 & aumento & 0,013 & céu 0,013 \\
\hline 9 & desperdicio & 0,010 & lixos 0,013 \\
\hline $10^{\circ}$ & cidade & 0,010 & aberto 0,013 \\
\hline $11^{\circ}$ & básico & 0,010 & desmatamento 0,011 \\
\hline $12^{\circ}$ & solo & 0,010 & ar 0,011 \\
\hline $13^{\circ}$ & áreas & 0,010 & construçăo 0,011 \\
\hline $14^{\circ}$ & saneamento & 0,009 & sujeira 0,009 \\
\hline $15^{\circ}$ & sonora & 0,009 & esgotos 0,009 \\
\hline $16^{\circ}$ & residuos & 0,009 & residuos 0,009 \\
\hline $17^{\circ}$ & uso & 0,009 & população 0,008 \\
\hline $18^{\circ}$ & emissão & 0,007 & terrenos 0,008 \\
\hline $19^{\circ}$ & empresas & 0,007 & doenças 0,006 \\
\hline $20^{\circ}$ & verdes & 0,007 & rio 0,006 \\
\hline
\end{tabular}

Gráfico 2 - Frequência relativa de termos mais utilizados nas respostas sobre impacto ambiental negativo. Fonte: Elaboração própria.

O Gráfico 3 apresenta a frequência relativa dos vinte termos mais frequentes utilizados nas respostas de escolas e igrejas para a pergunta "Como você caracterizaria a expressão "moradia segura e adequada"?". Observando no gráfico os termos respondidos, tanto para escolas como para as igrejas, percebe-se que os respondentes possuem clareza quanto à importância de elementos como saneamento básico, energia elétrica e água e segurança. Porém, também percebe-se que não são abordados temas relacionados ao tamanho (em relação à quantidade de residentes) e condições estruturais das edificações (como por exemplo, a qualidade dos materiais utilizados e a qualidade ou existência de projeto da edificação). 
Frequência relativa de termos mais utilizados nas respostas sobre moradia segura e adequada.

\begin{tabular}{|c|c|c|c|}
\hline & Escolas & & Igrejas \\
\hline $1^{\circ}$ & 0,030 & segurança & 0,063 \\
\hline $2^{*}$ & 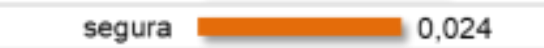 & pública & 0,025 \\
\hline $3^{\circ}$ & saneamento $\quad 0,022$ & àgua & 0,022 \\
\hline $4^{\circ}$ & segurança 0,019 & luz & 0,022 \\
\hline $5^{\circ}$ & condições $\quad 0,019$ & casa & 0,016 \\
\hline $6^{\circ}$ & adequada $=0,019$ & saneamento & 0,016 \\
\hline $7^{*}$ & serviços 0,016 & segura & 0,013 \\
\hline $8^{\circ}$ & esgoto 0,013 & esgoto & 0,013 \\
\hline 9 & ambiente 0,013 & básico & 0,013 \\
\hline $10^{\circ}$ & básicos $\quad 0,013$ & adequada & 0,013 \\
\hline $11^{\circ}$ & luz $\quad 0,013$ & familia & 0,013 \\
\hline $12^{n}$ & casa $\quad 0,011$ & risco & 0,013 \\
\hline $13^{\circ}$ & riscos 0,011 & condições & 0,013 \\
\hline $14^{\circ}$ & bairros $\quad 0,011$ & viver & 0,013 \\
\hline $15^{\circ}$ & espaço $\quad 0,011$ & seguro & 0,009 \\
\hline $16^{\circ}$ & elétrica $\quad 0,011$ & habitação & 0,009 \\
\hline $17^{\circ}$ & moradores $\quad 0,008$ & iluminação & 0,009 \\
\hline $18^{\circ}$ & básico 0,008 & ruas & 0,009 \\
\hline $19^{\circ}$ & morar $\quad 0,008$ & saúde & 0,009 \\
\hline $20^{\circ}$ & saúde $\quad 0,008$ & vida & 0,009 \\
\hline
\end{tabular}

Gráfico 3 - Frequência relativa de termos mais utilizados nas respostas sobre moradia segura e adequada. Fonte: Elaboração própria.

O Gráfico 4 apresenta a frequência relativa dos vinte termos mais frequentes utilizados nas respostas de escolas e igrejas para a pergunta "Em sua opinião, qual a principal ferramenta/recurso para orientar o crescimento e organização de uma cidade de forma sustentável?". Considera-se relevante mencionar que, embora haja a presença de termos relevantes como "educação", "conscientização" e "planejamento", entre outros, o termo "plano_diretor"5 não é utilizado. 0 termo é citado apenas uma vez nas respostas das escolas e também uma vez nas respostas das igrejas.

Os resultados apresentados no Gráficos 1, 2, 3 e 4 demonstram que os respondentes demonstraram possuir uma percepção conceitual adequada a respeito do temas dos quais foram questionados. Este fato pode indicar que a participação das suas instituições no SERP tenha contribuído para o alinhamento de suas percepções sobre desenvolvimento urbano sustentável.

Os Gráficos 5 e 6 apresentam os resultados da análise dos níveis de percepção e interesse dos integrantes das escolas e igrejas, sobre temas relacionados ao engajamento social no processo de planejamento da cidade, e à questão da relevância das parcerias intersetoriais para ações voltadas ao desenvolvimento urbano sustentável ${ }^{6}$. Para as respostas foi utilizada uma escala numérica progressiva, na qual o menor valor o pior resultado e o maior valor o melhor resultado.

\footnotetext{
5 Utiliza-se a sublinha para unir as palavras "plano" e "diretor" para que sejam contadas como um único termo.

${ }^{6} \mathrm{O}$ número no nome de cada barra dos gráficos corresponde à pergunta realizada no questionário do Apêndice $\mathrm{B}$.
} 


\section{Frequência relativa de termos mais utilizados nas respostas sobre a principal ferramenta para orientar o desenvolvimento de uma cidade sustentável.}

\section{Escolas}

\begin{tabular}{|c|c|c|c|c|}
\hline $1^{\circ}$ & educação & 0,074 & educação & 0,048 \\
\hline $2^{\circ}$ & conscientizaçăo & 0,074 & conscientização & 0,041 \\
\hline $3^{\circ}$ & planejamento & 0,044 & populaçăo & 0,041 \\
\hline $4^{\circ}$ & sustentável & 0,029 & palestras & 0,027 \\
\hline $5^{\circ}$ & informação & 0,029 & assunto & 0,021 \\
\hline $6^{\circ}$ & comunidade & 0,022 & alguém & 0,021 \\
\hline $7{ }^{\circ}$ & ferramenta & 0,022 & empresas & 0,014 \\
\hline $8^{\circ}$ & projetos & 0,022 & pessoas & 0,014 \\
\hline $9^{\circ}$ & campanhas & 0,022 & divulgaçăo & 0,014 \\
\hline $10^{*}$ & internet & 0,015 & saúde & 0,014 \\
\hline $11^{*}$ & principal & 0,015 & escolas & 0,014 \\
\hline $12^{*}$ & esclarecimento & 0,015 & comunicação & 0,014 \\
\hline $13^{\circ}$ & pública & 0,015 & trabalho & 0,014 \\
\hline $14^{*}$ & cidade & 0,015 & iniciativa & 0,014 \\
\hline $15^{\circ}$ & comunitário & 0,007 & conversas & 0,014 \\
\hline $16^{\circ}$ & educar & 0,007 & informação & 0,014 \\
\hline $17^{*}$ & sustentabilidade & 0,007 & sociedade & 0,014 \\
\hline $18^{\circ}$ & rede & 0,007 & frente & 0,014 \\
\hline $19^{*}$ & correta & 0,007 & leis & 0,014 \\
\hline $20^{\circ}$ & provavelmente & 0,007 & diretor & 0,007 \\
\hline
\end{tabular}

Gráfico 4 - Frequência relativa de termos mais utilizados nas respostas sobre a principal ferramenta para orientar o desenvolvimento de uma cidade sustentável. Fonte: Elaboração própria.

O Gráfico 5 apresenta as respostas referentes aos integrantes das escolas, com escala numérica de resposta entre zero e seis.

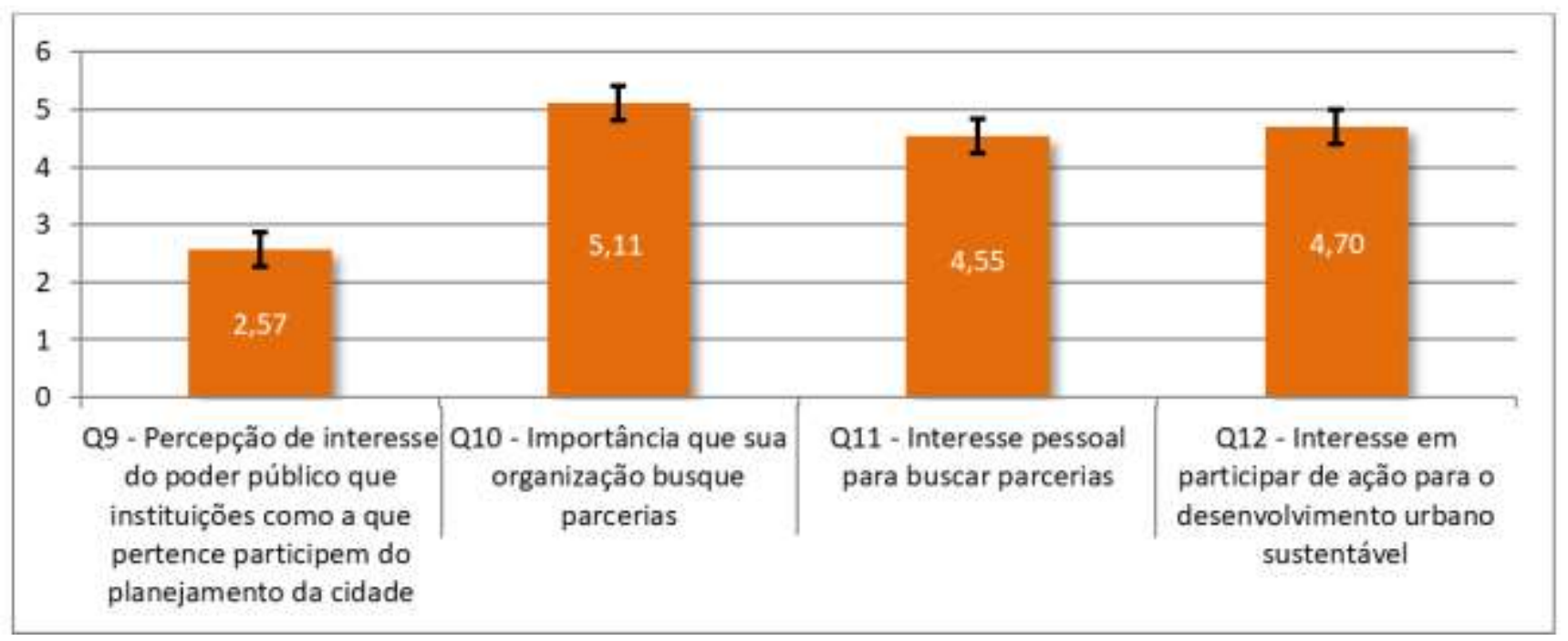

Gráfico 5 - Análise de percepção sobre relevância do engajamento intersetorial para intervenções orientadas ao desenvolvimento urbano sustentável - escolas. Fonte: Elaboração própria. 
0 Gráfico 6 apresenta as respostas referentes aos integrantes das igrejas, com escala numérica de resposta entre zero e cinco $^{7}$.

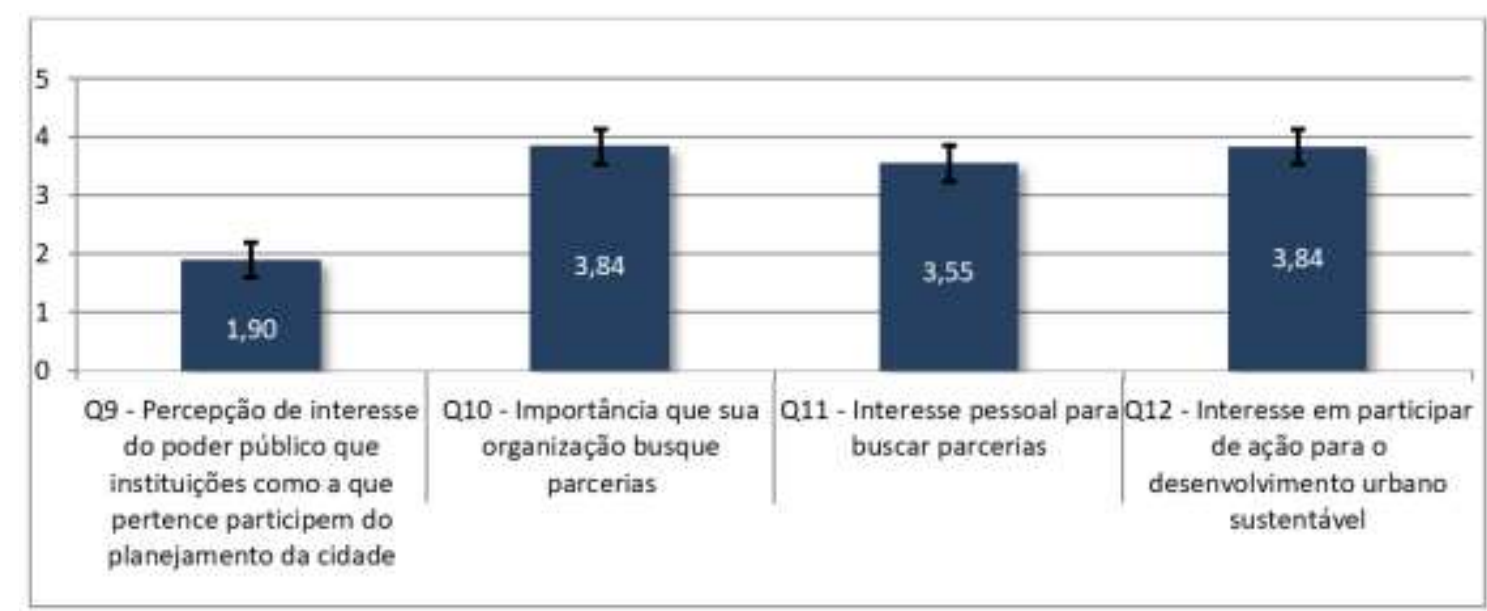

Gráfico 6 - Análise de percepção sobre relevância do engajamento intersetorial para intervenções orientadas ao desenvolvimento urbano sustentável - igrejas. Fonte: Elaboração própria.

Os resultados semelhantes entre as médias das respostas da Q9, os quais ficaram abaixo do valor médio das escalas possíveis, permitem inferir que tanto os respondentes das escolas como os das igrejas, ainda não identificaram no poder público o interesse em aproximar suas instituições do processo de planejamento urbano. Já os resultados das médias de Q10, Q11 e Q12, os quais ficaram acima do valor médio das escalas possíveis, permitem inferir que os integrantes, tanto de escolas como das igrejas, tendem a reconhecer o valor positivo das parcerias intersetoriais e também interagir com parcerias para o desenvolvimento urbano sustentável quando possível. É interessante notar que este resultado mais baixo da Q9 aparece mesmo no contexto no qual se dá a pesquisa, em que é o próprio poder público que está viabilizando a implementação da EDS e do SERP para que suas instituições participem.

\section{Percepção de Benefícios da Implementação da EDS}

Com o propósito de identificar a percepção dos potenciais benefícios de aplicação da metodologia, segundo a percepção dos profissionais que compuseram a equipe de trabalho ou tiveram contribuição próxima ao processo, foi aplicado o questionário de percepção de melhorias a partir do uso da EDS. Dos profissionais abordados, seis responderam ao questionário ${ }^{8}$.

O Gráfico 7 apresenta os benefícios decorrentes da utilização da EDS, percebidos quando respondida a questão "Se você percebe benefícios diretos à sua organização, decorrentes da implementação da EDS, relacione-os abaixo". As respostas foram organizadas e sumarizadas segundo o tema ao qual se referiam.

\footnotetext{
${ }^{7}$ Esta diferença entre os valores de escala de respostas entre escolas e igrejas, deve-se a um ajuste metodológico, de escala ímpar para escala par, de modo a evitar respostas do tipo "neutro" no meio da escala. Porém a decisão de ajuste deu quando os questionários das escolas já estavam sendo respondidos. Assim, optou-se por manter 0 a 6 para escolas e ajustar de 0 a 5 para igrejas, já que ambos os resultados não serão comparados entre si.

8 Destes seis, três são da equipe da EDS (que no momento de aplicação do questionário possuía seis integrantes) e os outros três são técnicos envolvidos nos processos de trabalho influenciados pela EDS, em especial em relação ao SERP.
} 


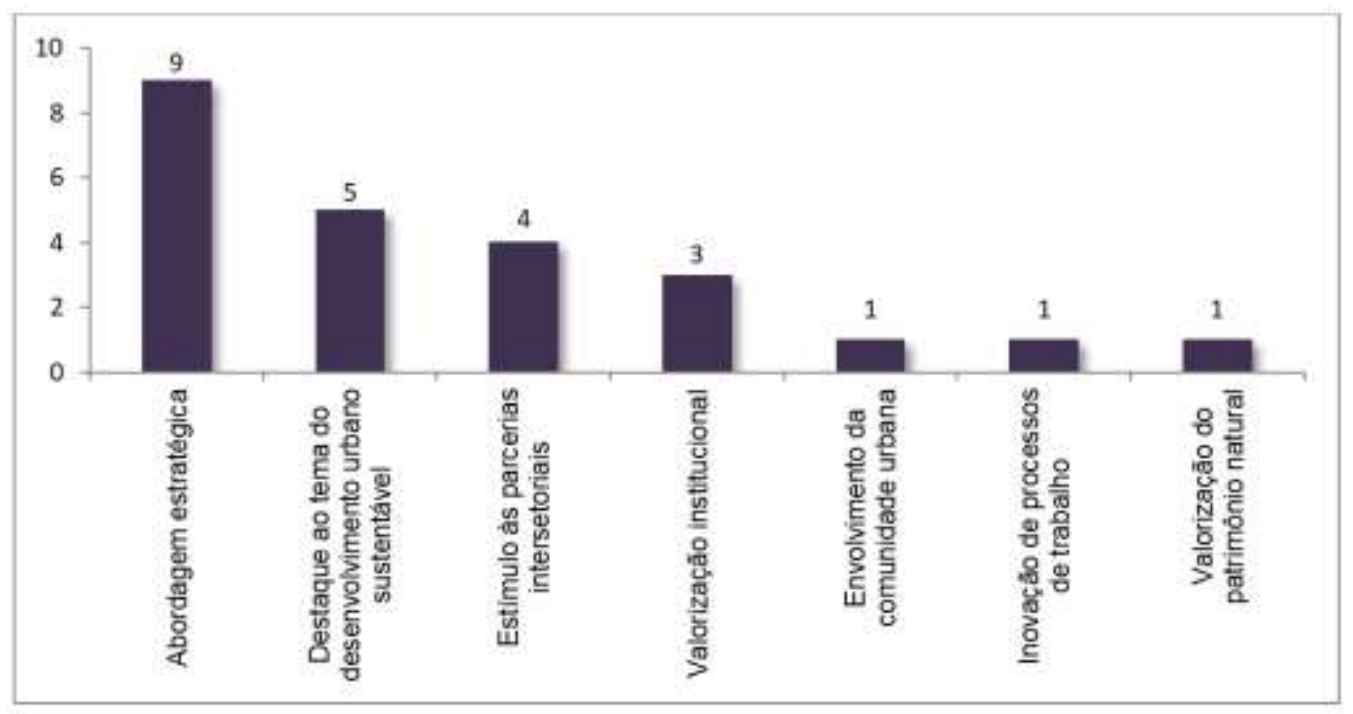

Gráfico 7 - Benefícios diretos decorrentes da implementação da EDS. Fonte: Elaboração própria.

A segunda pergunta realizada teve por propósito identificar o nível de engajamento geral da equipe EDS percebido por seus próprios integrantes (Gráfico 8). É interessante notar a importância dada à atividade de supervisão do processo (evidenciadas através das respostas indicando que as pessoas aumentam seu nível de atuação quando se sentem supervisionadas).

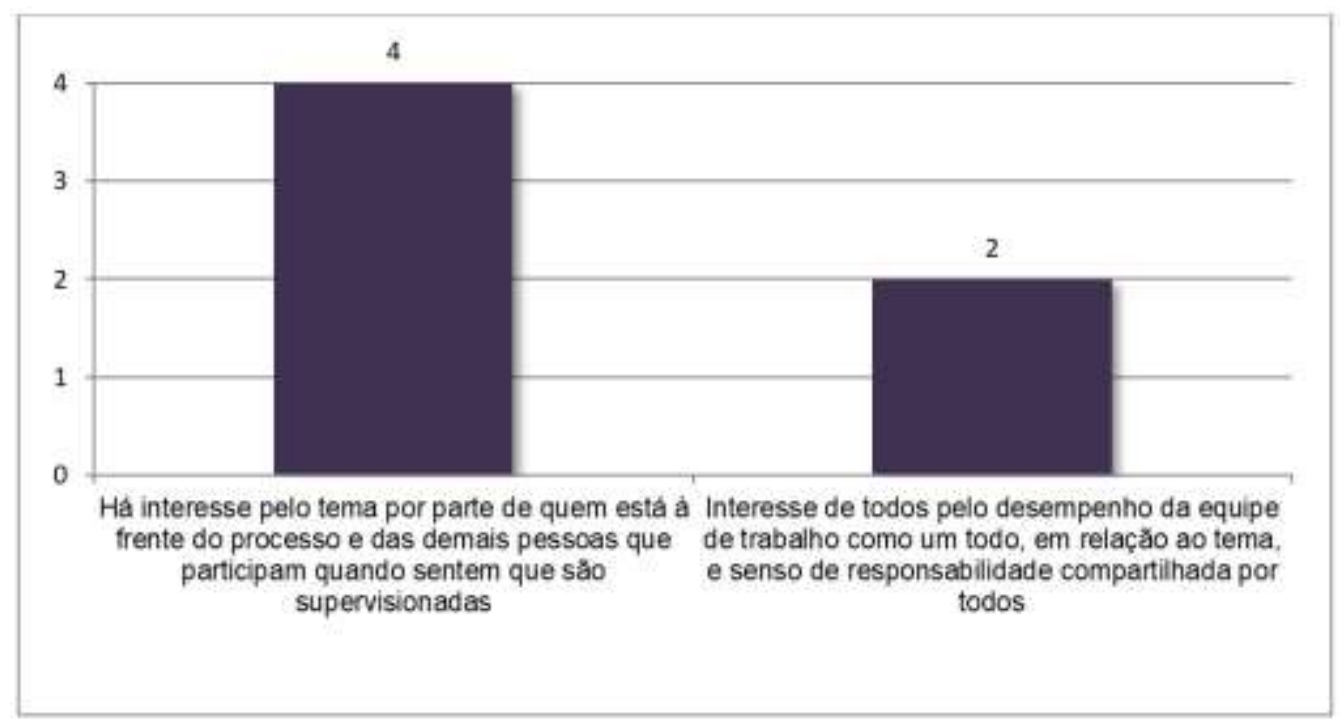

Gráfico 8 - Características que melhor descrevem a atitude dos integrantes da equipe EDS. Fonte: Elaboração própria.

Embora as respostas do Gráfico 8 possam sugerir a possibilidade de baixo nível de interesse no processo no qual as pessoas estavam inseridas, nas justificativas para estas respostas (na questão três do mesmo questionário), foram apresentadas explicações como "grande demanda de trabalho", referente a outras atividades desempenhadas pelos profissionais em seus locais de trabalho, e necessidade de tempo para internalização dos processos. Todas as respostas da questão três evidenciaram percepção positiva quanto ao envolvimento e participação dos profissionais no processo da EDS.

Com base nas informações apresentadas, percebe-se que houve avaliação positiva da metodologia implementada, com benefícios reconhecidos pelos profissionais que participaram do processo. Foi também informado pela prefeitura de Guaíba (RS), que a metodologia seguirá sendo utilizada mesmo após o término da pesquisa. 


\section{Considerações finais}

Ao longo do processo de realização da pesquisa e com base nos resultados observados, é possível perceber a relevância da articulação intersetorial para a promoção de práticas relacionadas ao desenvolvimento urbano sustentável, bem como quanto a prática da intersetorialidade é desafiadora no âmbito da gestão urbana. E neste contexto, percebe-se que a utilização de um modelo de gestão como a EDS, por possuir etapas processuais bem definidas, apresenta potencial para contribuir positivamente para a articulação intersetorial voltada ao desenvolvimento sustentável de uma cidade de médio porte. Isto se deve ao fato de que a estrutura da EDS, conforme percebido ao longo de sua implementação, estimula constantemente a busca por colaboração de organizações e representantes de diferentes segmentos, não somente dentro da gestão municipal, como também junto a outros níveis de governo, setor privado e sociedade civil (em atividades que vão desde a coleta de dados até execução e monitoramento de intervenções realizadas).

A aplicação prática do processo da EDS permitiu identificar que este modelo pode ser utilizado em sua totalidade como instrumento de proposição e gestão de programas e projetos de desenvolvimento urbano por governos municipais. Dois benefícios diretos foram percebidos com a implementação do processo. 0 primeiro deles a organização e sistematização de informações existentes no município que foram utilizadas para o diagnóstico situacional e das informações de projetos relacionados às metas do ODS-11 no município. O segundo benefício foi a possibilidade de elaboração de projetos baseados em dados do diagnóstico que fossem concebidos intersetorialmente, com foco específico no desenvolvimento urbano sustentável.

Entretanto, quando considerada a amplitude de possíveis intervenções urbanas que visem atender às metas do ODS-11, percebe-se que o período de realização da presente pesquisa (doze meses) permitiu apenas a operacionalização dos passos iniciais de implementação da EDS como um todo, para que assim passe a fazer parte do processo de gestão urbana como um todo. Esta percepção motivou a decisão de priorizar a implementação do SERP, por se tratar de um sistema com um ciclo operacional compatível com os prazos da pesquisa. Esta decisão não trouxe prejuízo ao processo como um todo, uma vez que foram mantidas as características de intersetorialidade e ênfase no engajamento de segmentos sociodemográficos, como de fato ocorreu com o engajamento que participaram direta e indiretamente do processo.

Foi interessante notar que a equipe multidisciplinar, composta pelos técnicos da prefeitura de Guaíba, enfrentou a necessidade de substituição de integrantes ao longo do processo de operacionalização da EDS. Os motivos para esta situação variaram desde desligamento do executivo municipal até questões de dificuldades no ambiente político dentro das secretarias envolvidas. Entretanto, os técnicos que permaneceram desde o início do processo demonstraram (por meio de sua prática profissional) real aprendizado da abordagem estratégica da EDS e do SERP, mais especificamente. Esta realidade ratifica a noção do alto grau de complexidade de implementação de processos baseados na multidisciplinaridade, mesmo quando se trata de uma prefeitura de um município de médio porte. Porém foi percebido que um processo, como o proposto, que contenha uma metodologia clara e objetiva, favorece o engajamento dos técnicos, uma vez que lhes facilita a atribuição de sentido às novas atividades nas quais passam a fazer parte.

Outro ponto foi considerado como determinante para que um modelo de gestão como a EDS tenha êxito, seja no contexto de pesquisa ou de processo de trabalho propriamente dito, é que haja o apoio político dos gestores que aceitam implementar o processo. Ao longo da realização da pesquisa, foi possível identificar que embora todos os secretários tenham recebido de forma aberta a implementação do modelo de gestão proposto neste trabalho, houve distinção no grau de engajamento efetivo dos mesmos ao longo do processo. Assim, pode-se dizer que houve os que abriram as portas de sua secretaria e os que para, além disto, também participarem na mesa de discussão da operacionalização do processo de trabalho. Com base nestes fatos, é possível assumir que a eventual implementação da EDS, em outros municípios, deverá ter como premissa fundamental a ênfase na articulação com os gestores locais a fim de que seu engajamento seja efetivo ao longo do processo como um todo.

A avalição do SERP como processo para a mobilização de segmentos específicos da população municipal, mostrou-se efetiva, uma vez que cumpriu o seu propósito de estimular a criação de projetos, por parte das instituições que aderiram ao sistema, e também pela capacidade de captação de novas parcerias entre instituições do setor público, setor privado e da sociedade civil. E neste ponto cabe destacar que esta forma de articulação de parcerias junto à comunidade da cidade alcançou um nível extra de capilaridade 
social, uma vez que ao invés de ter ficado centralizada na equipe técnica da prefeitura de Guaíba, foi realizada de forma decentralizada e voluntária por meio das instituições por meio das instituições participantes.

Outra vantagem percebida do SERP, é que na forma como foi concebido, o sistema estimulou a equipe técnica da prefeitura a focar na atividade de coordenação e gestão do processo, ao invés de se portar como uma promotora e executora de projetos e atividades. Este fato permite inferir que este sistema pode ser aplicado em outros municípios, inclusive de maior porte, para engajar outros segmentos da sociedade (para além dos que foram abordados no contexto desta pesquisa), e assim promover uma melhor alocação da capacidade de trabalho de equipes técnicas. Isto porque o sistema passa a ser uma ferramenta que estimula e favorece as atividades de coordenação e gestão e transfere de forma progressiva e lógica as atividades operacionais para as instituições que façam a adesão ao processo. Isto também tende a diminuir a distância entre a gestão municipal e a população, uma vez que estimula o senso de parceria e engajamento no desenvolvimento dos processos, inclusive do reconhecimento público por parte dos gestores por meio da certificação de desempenho dos participantes do processo.

0 desenvolvimento de um software para a gestão do processo de parcerias, desenvolvimento de projetos e cálculo das pontuações de certificação pode ser considerado como um ponto de destaque deste processo. Considerando que alguns dos grandes desafios de iniciativas intersetoriais no ambiente da gestão pública é a sistematização de informações sobre parcerias existentes, dados sistematizados sobre projetos em desenvolvimento ou em curso e informações de desempenho destes processos, é possível inferir que este instrumento pode ser aplicado por outros municípios. Tanto para a implementação do modelo de gestão proposto no presente trabalho, como também para outros processos de gestão orientados à intersetorialidade urbana.

Uma limitação desta pesquisa foi a quantidade de tempo utilizada para a sua aplicação. Considerando que a EDS visa auxiliar na articulação intersetorial e sistematização de processos de trabalho, o período de doze meses demonstrou-se curto para que a plena operacionalização do processo fosse realizada. É possível estimar que o período ideal para a implementação plena do processo e sua inicial estabilização como processo de trabalho seja entre 24 e 36 meses, de modo a viabilizar uma operação mais estável das etapas metodológicas aprendidas nos primeiros doze meses e um aumento do volume de dados para a avaliação do modelo como um todo. Esta limitação foi a que levou a opção de direcionar o foco da pesquisa para o SERP, permitindo que um ciclo inteiro de certificação fosse conduzido e avaliado. Entretanto, um período maior de tempo permitiria que fossem acompanhados novos ciclos de certificação, e assim a comparação entre os ciclos fosse adicionada ao processo de avaliação do SERP.

As limitações apresentadas também apontam para novas oportunidades para futuras pesquisas. Tendo em vista que os processos implementados durante a pesquisa demonstraram viabilidade para aplicação em um município de médio porte, identifica-se como oportunidade de pesquisa a implementação da EDS em outros municípios, por períodos maiores de tempo, visando uma melhor compreensão das fragilidades e potencialidades deste modelo de gestão. Neste mesmo sentido, também surgem oportunidades de novas pesquisas que sejam direcionadas a cada uma das seis etapas do modelo de gestão proposto, especialmente no que diz respeito às atividades de monitoramento e avaliação de iniciativas de desenvolvimento urbano sustentável.

Tanto a EDS como modelo de gestão, e mais especificamente o processo do SERP, foram identificados como abordagens que podem contribuir para a promoção de iniciativas orientadas ao desenvolvimento urbano sustentável. Sua ênfase em intersetorialidade e aprimoramento progressivo, demonstram potencialidade para que sejam implementadas em outras cidades brasileiras. A eventual implementação em novas cidades apresenta oportunidades de desenvolvimento e refinamento tanto para a metodologia em si (ao passar pelo teste de novas implementações práticas), como também para a qualificação dos processos de gestão urbana de cidades que desejem se desenvolver de forma sustentável e assim promoverem condições urbanas melhores para as futuras gerações.

\section{Referências}

Cardita, J., \& Pietro, G. (2010). Estratégia de proatividade e parceria: um modelo de participação comunitária para abordar a 
segurança no trânsito. Genebra: Global Road Safety Partnership.

Collis, J., \& Hussey, R. (2005). Pesquisa em administração: um guia prático para alunos de graduação e pós-graduação (2a ed.). Porto Alegre: Bookman.

Departamento de Informática do SUS - DATASUS. (2017). População Residente - Estimativas para o TCU - Brasil. Recuperado em 25 de novembro de 2017, de http://tabnet.datasus .gov.br/cgi/tabcgi.exe?ibge/cnv/poptbr.def.

Institute for the Advanced Study of Sustainability. (2016). Sustainable urban future: cities and climate change. Recuperado em 18 de novembro de 2016, de http://urban.ias.unu.edu/index.php/cities-and-climate-change/.

Johnson, S. (2003). Emergência: a dinâmica de rede em formigas, cérebros, cidades e softwares. Rio de janeiro: Zahar.

Leite, C., \& Awad, J. M. (2012). Cidades sustentáveis, cidades inteligentes: desenvolvimento sustentável num planeta urbano. Porto Alegre: Bookman.

Pascale, R. (1999). Surfing the edge of chaos. MIT Sloan Management Review. Recuperado em 11 de julho de 2020, de https://sloanreview.mit.edu/article/surfing-the-edge-of-chaos.

Soares, P. R., \& Fedozzi, L. J. (2016). Porto Alegre e sua região metropolitana no contexto das contradições da metropolização brasileira contemporânea. Sociologias, 18(42), 162-197.

Spradley, J., \& McCurdy, D. (2006). Conformity and Conflict (12e, pp. 422-435). San Francisco: Pearson.

The World Bank. (2017). Urban population (\% of total). Recuperado em 27 de abril de 2017, de http://data.worldbank.org/indica tor/SP.URB.TOTL.IN.ZS?page=3.

Tripp, D. (2005). Action research: a methodological introduction. Educação e Pesquisa, 31(3), 443-466.

Vergara, S. C. (2010). Métodos de pesquisa em administração (4a ed.). São Paulo: Atlas.

Editor responsável: Rodrigo Firmino

Recebido: 17 mar. 2020

Aprovado: 17 nov. 2020 